\title{
THE EFFECT OF INSULIN HYPOGLYCEMIA ON THE CIRCULATION ${ }^{1}$
}

\author{
By A. CARLTON ERNSTENE AND MARK D. ALTSCHULE
}

(From the Medical Research Laboratories, Beth Israel Hospital, and the Department of Medicine, Harvard Medical School, Boston)

(Received for publication April 25, 1931)

Several observers have directed attention to the fact that insulin hypoglycemia may precipitate symptoms and signs of serious disturbance in the cardiovascular system. Gigon (1), in 1923, reported that a patient with diabetes mellitus had died from myocardial failure after the third dose of insulin. Reinwein (2) observed two patients with diabetes mellitus and circulatory insufficiency in whom the administration of insulin caused a decided increase in the degree of congestive failure. Joslin (3) and Blotner (4) reported cases in which cardiac infarction developed shortly after the administration of insulin, and von Noorden and Isaac (5) observed several patients with coronary artery disease in whom insulin hypoglycemia apparently was the cause of death. Several instances have been recorded in which insulin hypoglycemia precipitated typical attacks of angina pectoris $(6,7,8)$.

Further evidence of altered cardiac physiology during insulin hypoglycemia is afforded by the electrocardiographic studies of Middleton and Oatway (9) and others. The changes observed consisted of diminished amplitude or inversion of the T-wave.

Although the effect of insulin shock on the pulse rate and arterial blood pressure of man has been studied by several investigators (10, $11,12,13)$, but little attention has been paid to the effect of the hypoglycemic state on the minute volume output of the heart. In the only reported measurements, Lauter and Baumann (13), using the ethyl iodide method of Henderson and Haggard (14), recorded an increased circulatory minute volume during hypoglycemia in five

\footnotetext{
${ }^{1}$ This investigation was aided by a grant from the DeLamar Mobile Research Fund of Harvard University.
} 


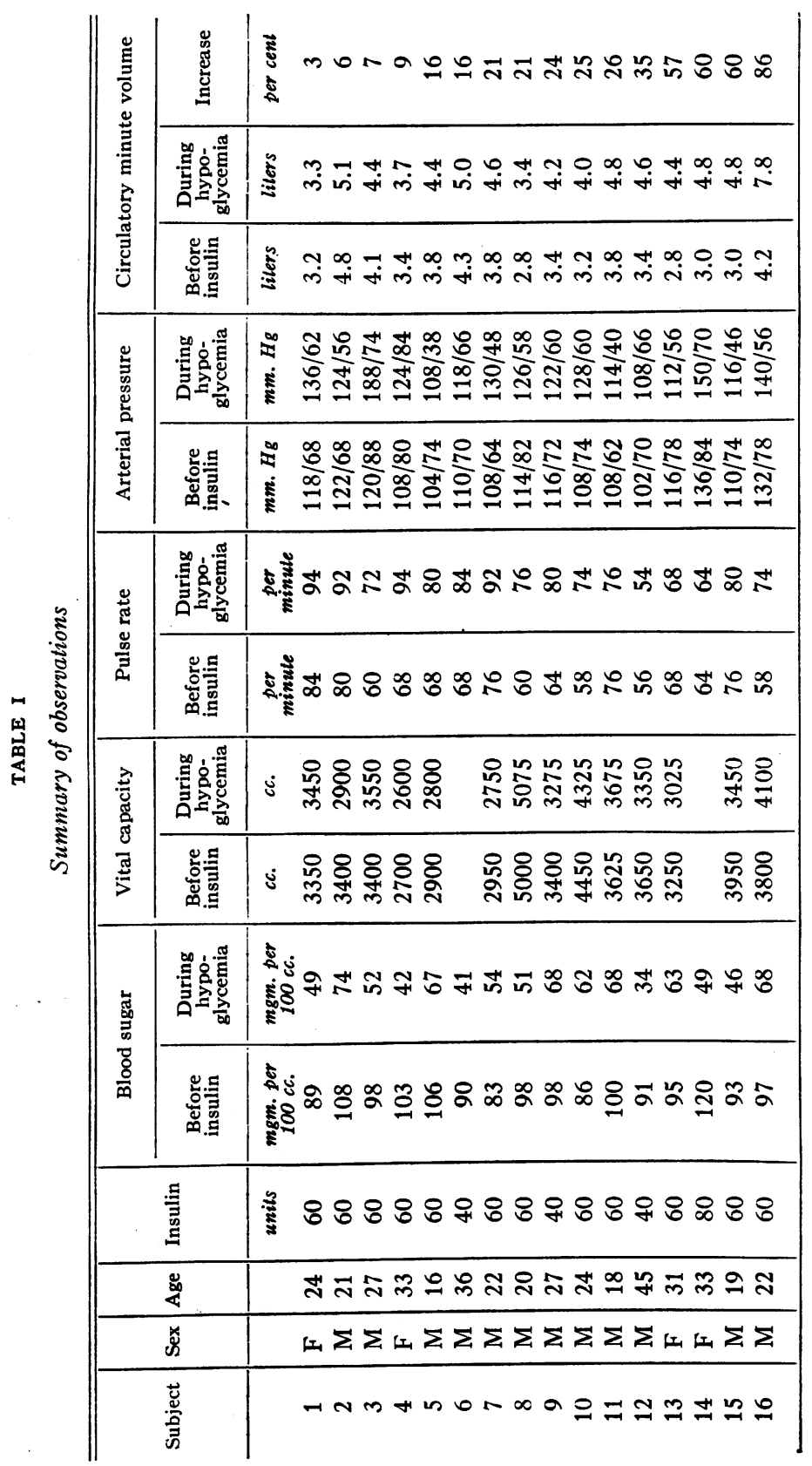


patients with diabetes mellitus and one normal subject. Because of the serious cardiovascular disturbances following the administration of insulin in certain patients, further investigation of the effect of insulin hypoglycemia on the circulation seemed desirable.

\section{METHOD OF STUDY}

All observations were made while the subjects were in the postabsorptive state, in bed, in a semi-recumbent position. The fasting blood sugar content was determined according to the method of Folin and $\mathrm{Wu}$ (15). The vital capacity of the lungs was measured, and the arterial blood pressure and the pulse rate were recorded at frequent intervals. When the two latter had become constant, the circulatory minute volume was measured according to the acetylene method of Grollman (16). Immediately after the second rebreathing period, 40 to 80 units of insulin were administered subcutaneously. The blood pressure and pulse rate were recorded at ten-minute intervals until the end of the experiment. The signs and symptoms of hypoglycemia were noted as they appeared. Profuse perspiration usually developed 45 to 90 minutes after the administration of insulin. When this state was reached, a second sample of blood was collected for estimation of the sugar content; the pulse rate and blood pressure were again recorded, and a second measurement of the minute volume output of the heart was made. A third specimen of blood was then collected, the pulse rate, blood pressure, and vital capacity of the lungs were recorded, and finally the subject was given $500 \mathrm{cc}$. of orange juice followed by a large breakfast rich in carbohydrate.

\section{RESULTS}

Sixteen normal, non-diabetic subjects between the ages of 16 and 4,5 years were studied. A summary of the observations is presented in Table $I$, and the protocol of a representative experiment is shown in Table II. The initial sugar content of the blood was within the limits of normal in all instances, while the lowest recorded content at the end of the experiments varied from 34 to $74 \mathrm{mgm}$. per $100 \mathrm{cc}$. All subjects displayed characteristic symptoms and signs of hypoglycemia at the time of the second measurement of the cardiac minute volume output, but they had not become restless or anxious. 
TABLE II

Protocol of a representative experiment

Subject 5. Aet. 16. Height 64 inches. Weight 115 pounds

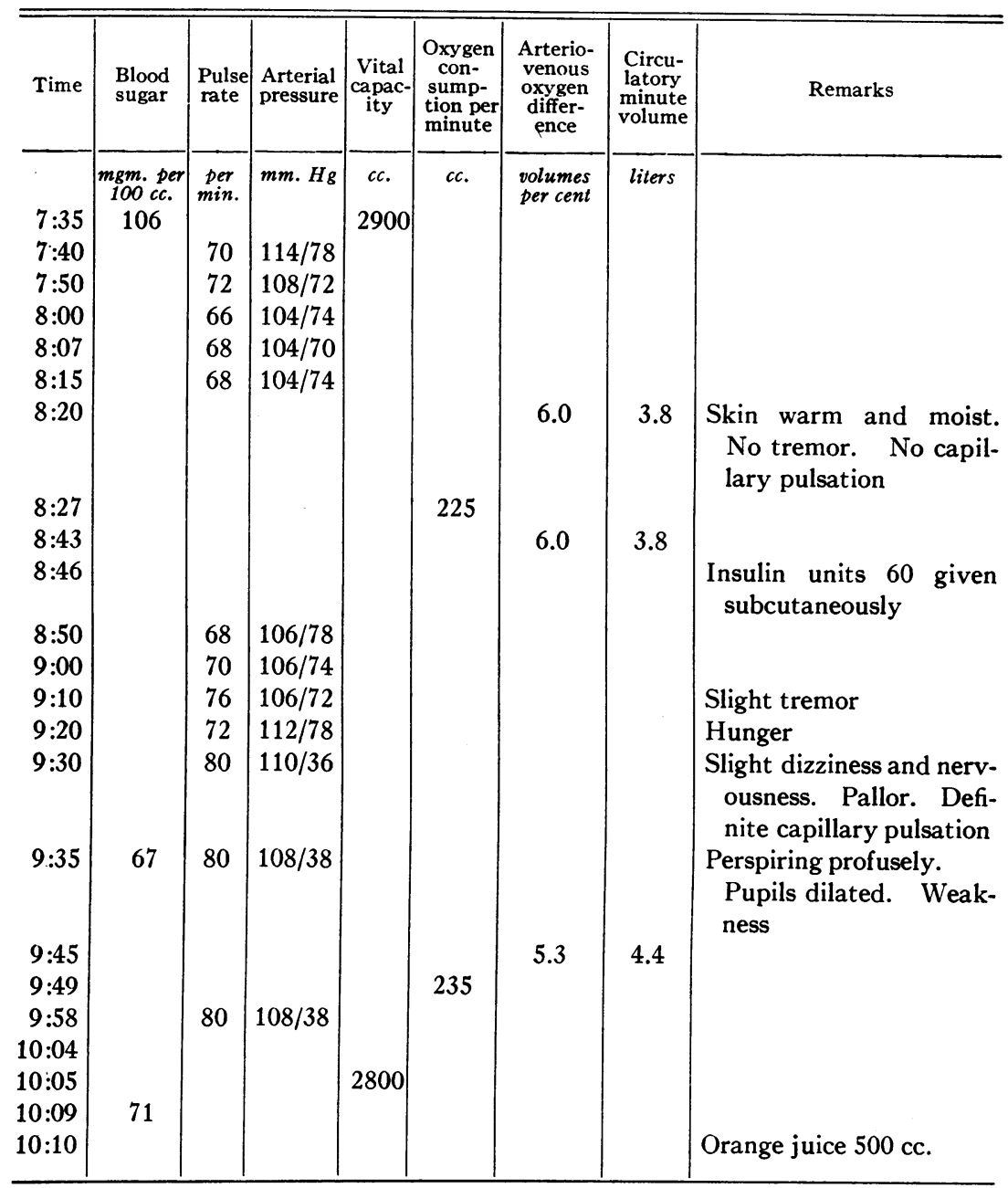

During hypoglycemia, the minute volume output of the heart increased in every subject, although occasionally not beyond the limits of error. The increase averaged 29 per cent and varied in different individuals from 3 per cent to 86 per cent. No correlation between 
the rise in circulatory minute volume and the fall in blood sugar level could be demonstrated. The pulse pressure increased in all subjects, the average change being $29 \mathrm{~mm}$. of mercury. Usually the systolic blood pressure rose, while the diastolic fell. Capillary pulsation was observed in 12 of 13 subjects examined for its presence. In 11 instances, there was a distinct rise in pulse rate, averaging 15 beats per minute. Average values for pulse rate, arterial pressure, pulse pressure and circulatory minute volume before and during hypoglycemia are presented in Table III.

TABLE III

Average values before and during hypoglycemia

\begin{tabular}{|c|c|c|c|c|}
\hline & Pulse rate & $\begin{array}{l}\text { Arterial } \\
\text { pressure }\end{array}$ & $\begin{array}{c}\text { Pulse } \\
\text { pressure }\end{array}$ & $\begin{array}{l}\text { Circulatory } \\
\text { minute volume }\end{array}$ \\
\hline $\begin{array}{l}\text { Before insulin } \ldots \ldots \ldots \ldots \ldots \ldots \\
\text { During hypoglycemia } \ldots \ldots \ldots \ldots\end{array}$ & \begin{tabular}{|c|} 
per minute \\
68 \\
78
\end{tabular} & $\begin{array}{l}m m . ~ H g \\
114 / 74 \\
128 / 59\end{array}$ & $\begin{array}{c}\text { mm. } \mathrm{Hg} \\
40 \\
69\end{array}$ & $\begin{array}{c}\text { liters } \\
3.56 \\
4.58\end{array}$ \\
\hline Percentage change. . & +15 & $+12 /-20$ & +73 & +29 \\
\hline
\end{tabular}

In five individuals the vital capacity decreased by 200 to $500 \mathrm{cc}$., while in two it increased by more than $100 \mathrm{cc}$.

\section{DISCUSSION}

The results of the present investigation furnish a rational explanation for the occurrence of cardiovascular disturbances during insulin hypoglycemia. They indicate that hypoglycemia usually is attended by an increase in the minute volume output of the heart, the pulse pressure and the ventricular rate. These findings denote a considerable increase in the amount of cardiac work. In normal individuals the heart easily accomplishes this increased work. In subjects with diminished myocardial reserve, however, the added work may give rise to conspicuous signs and symptoms of myocardial insufficiency. In other individuals attacks of angina pectoris may be precipitated.

In connection with the chain of events whereby insulin hypoglycemia leads to the observed changes in the circulation, certain observations on animals by Cannon, McIver and Bliss (17) are of considerable interest. According to these investigators, the symptoms and signs of insulin shock result from stimulation of the sympathetic 
division of the autonomic nervous system. In cats whose hearts had been denervated completely and in which one adrenal gland had been removed and the other denervated, the heart rate did not increase during hypoglycemia as it did in animals with denervated hearts but with intact adrenal glands. Cannon, McIver and Bliss, therefore, concluded that the increase in heart rate under these conditions results from a discharge of adrenine in response to stimulation of the sympathetic nerves to the adrenals.

Clinically, the changes in pulse rate, systolic and diastolic blood pressure and cardiac minute volume output that occur during insulin hypoglycemia are similar to those that follow subcutaneous administration of epinephrine $(18,19)$. Capillary pulsation also may appear in both conditions $(12,20)$. According to Boothby and Wilder (21), insulin has no direct effect on the metabolic rate. They suggested that the increased metabolism recorded during hypoglycemia results from a spontaneous discharge of epinephrine. These observations lend further support to the hypothesis that the circulatory changes observed during hypoglycemia in man result mainly from stimulation of the sympathetic system and increased discharge of adrenine.

The increased cardiac work incident to hypoglycemia probably is of particular importance if hypoglycemia develops during the treatment of diabetic coma. The observations of Foster (22) suggest that, in the presence of ketosis, the heart is less able than normally to accomplish the work demanded of it. He observed myocardial degeneration at necropsy in patients dying in diabetic coma. The weakened heart action frequently observed clinically in diabetic coma is in harmony with these findings. In the light of these observations it is not altogether surprising that patients may die from myocardial failure in spite of the fact that the manifestations of diabetic coma have been treated successfully with insulin (13).

In brief, not only is the heart called upon to perform more work in insulin hypoglycemia, but in certain subjects it is probably less capable than normally of responding to these increased demands. The results of the present investigation suggest that great care should be taken to avoid hypoglycemia in subjects with arteriosclerosis, angina pectoris, or symptoms and signs of circulatory insufficiency, particularly when ketosis is present. Under such circumstances, hypoglycemia usually 
can be avoided by giving smaller amounts of insulin at more frequent intervals, by repeated measurements of the blood sugar content and, when necessary, by the administration of glucose.

\section{SUMMARY}

1. The effect of insulin hypoglycemia on the pulse rate, arterial blood pressure, minute volume output of the heart and vital capacity of the lungs was measured in sixteen normal non-diabetic individuals.

2. The pulse rate and pulse pressure increased during hypoglycemia, the systolic blood pressure rising, while the diastolic fell.

3. The minute volume output of the heart increased during hypoglycemia.

4. These observations indicate that insulin hypoglycemia is attended by an increased amount of cardiac work.

5. This increased cardiac work furnishes a rational explanation for the clinical observation that, in subjects with diminished myocardial reserve, hypoglycemia may result in the development of conspicuous signs and symptoms of myocardial failure. It also serves to explain the occurrence of attacks of angina pectoris in certain individuals during hypoglycemia.

6. The results of the investigation suggest that great care should be taken to avoid hypoglycemia in subjects with arteriosclerosis, angina pectoris, or with symptoms and signs of circulatory insufficiency, particularly when ketosis is present.

\section{BIBLIOGRAPHY}

1. Gigon, Klin. Wchnschr., 1923, ii, 1670. Diabetes und Insulintherapie (Verhandl. med. Gesellsch., Basel).

2. Reinwein, H., Deutsch. med. Wchnschr., 1929, lv, 951. Aussergewöhnliche Insulinschädigungen des Kreislaufs und ihre Folgen für den Kohlenhydratstoff wechsel.

3. Joslin, E. P., The Treatment of Diabetes Mellitus, Philadelphia, Lea and Febiger, 1928, 4th ed.

4. Blotner, H., New England J. Med., 1930, cciii, 709. Coronary Disease in Diabetes Mellitus.

5. von Noorden, C. and Isaac, S., Die Zuckerkrankheit und ihre Behandlung, Berlin, Julius Springer, 1927, 8th ed.

6. Hetényi, G., Wien. Arch. f. inn. Med., 1926, xiii, 95. Angina pectoris während Insulinbehandlung. 
7. Katz, G. I., Odessky Med. J., 1929, iv, 207. The Rôle of Hormones in the Pathogenesis of Angina Pectoris.

8. Turner, K. B., Am. Heart J., 1930, v, 671. Insulin Shock as the Cause of Cardiac Pain.

9. Middleton, W. S. and Oatway, W. H., Jr., Am. J. Med. Sci., 1931, clxxxi, 39. Insulin Shock and the Myocardium.

10. Fletcher, A. A. and Campbell, W. R., J. Metab. Res., 1922, ii, 637. The Blood Sugar Following Insulin Administration and the Symptom Complex-Hypoglycemia.

11. Lyman, R. S., Nicholls, E. and McCann, W. S., J. Pharmacol. and Exp. Therap., 1923, xxi, 343. The Respiratory Exchange and Blood Sugar Curves of Normal and Diabetic Subjects after Epinephrin and Insulin.

12. Wiechmann, E. and Koch, F., Deutsch. Arch. f. klin. Med., 1929, clxiii, 176. Untersuchungen über den hypoglykämischen Zustand nach Insulininjektion. III. Das Verhalten des Kreislaufs im hypoglykämischen Zustand.

13. Lauter, S. and Baumann, H., Deutsch. Arch. f. klin. Med., 1929, clxiii, 161. Kreislauf und Atmung im hypoglykämischen Zustand.

14. Henderson, Y. and Haggard,. H. W., Am. J. Physiol., 1925, lxxiii, 193. The Circulation and its Measurement.

15. Folin, O. and Wu, H., J. Biol. Chem., 1920, xli, 367. A System of Blood Analysis. I. A Simplified and Improved Method for Determination of Sugar.

16. Grollman, A., Am. J. Physiol., 1929, lxxxviii, 432. The Determination of the Cardiac Output of Man by the Use of Acetylene.

17. Cannon, W. B., McIver, M. A. and Bliss, S. W., Am. J. Physiol., 1924, lxix, 46. Studies on the Condition of Activity in Endocrine Glands. XIII. A Sympathetic and Adrenal Mechanism for Mobilizing Sugar in Hypoglycemia.

18. Jensen, J., Am. Heart J., 1930, v, 763. The Adrenalin Test in Hypertension.

19. Euler, U. and Liljestrand, G., Skandinav. Arch. f. Physiol., 1927, lii, 243. Die Wirkung des Adrenalins auf das Minutenvolumen des Herzens beim Menschen.

20. Weiss, S.: Personal communication.

21. Boothby, W. M. and Wilder, R. M., Med. Clin. N. Am., 1923, vii, 53. Preliminary Report on the Effect of Insulin on the Rate of Heat Production and its Significance in Regard to the Calorigenic Action of Adrenalin.

22. Foster, N. B., J. Am. Med. Assoc., 1925, lxxxiv, 719. Diabetic Coma. 